\title{
Frequency of Diabetes and Prediabetes in Heart Failure Patients and Their Association with In-Hospital Outcome
}

\author{
Noortaj Begum ${ }^{1 *}$ \\ Abu Sadique Abdullah ${ }^{2}$ \\ Md. Aminul Haque Khan \\ AN Wahida Suatana ${ }^{3}$ \\ DMMF Osmany² \\ Forhadul Hoque Mollah ${ }^{4}$ \\ 'Department of Biochemistry \\ Enam Medical College \\ Dhaka, Bangladesh. \\ ${ }^{2}$ Department of Cardiology \\ Bangabandhu Sheikh Mujib Medical University \\ Dhaka, Bangladesh. \\ ${ }^{3}$ Dhaka Mohanagar General Hospital \\ Dhaka, Bangladesh \\ ${ }^{4}$ Department of Biochemistry \\ Bangabandhu Sheikh Mujib Medical University \\ Dhaka, Bangladesh.
}

\section{*Correspondence to:}

\section{Dr. Noortaj Begum}

Department of Biochemistry

Enam Medical College, Savar

Dhaka, Bangladesh.

Mobile: +8801199198926

E-mail: russeldmc@yahoo.com

\begin{abstract}
Background: There are an increasing number of hospital admissions due to heart failure with diabetes or prediabetes in different hospitals in Bangladesh. But very little is known about the frequency of diabetes and prediabetes and the effect of its presence on the characteristics and outcome in patients hospitalized for heart failure. The objective of this study was to find out the frequency of diabetes and prediabetes in heart failure patients and to assess their association with in-hospital outcome. Methods: This cross sectional analytical study was done in the department of Biochemistry and Cardiology of Bangabandhu Sheikh Mujib Medical University in collaboration with department of Cardiology of National Institute of Cardiovascular Diseases, and Dhaka Medical College Hospital from July 2010 to June 2011. After proper ethical consideration a total two hundred and fifty heart failure patients were enrolled in the study by nonrandom sampling. Fasting blood sugar was done in all patients and oral glucose tolerance test was done in patients with impaired fasting glycaemia. Results: The frequency of prediabetes among the total population was $12.8 \%$ (95\% CI, 8.7-16.8) and that of diabetes was 37.2\% (95\% CI, 31.2-43.2\%). Improvement was achieved in $27(84.4 \%)$ cases in prediabetic group, $75(80.6 \%)$ cases in diabetic group and $105(84.0 \%)$ cases in nondiabetic group. Mortality rates in prediabetes, diabetes and nondiabetes were 5 (15.6\%); 18 (19.4\%) and $20(16.0 \%)$ respectively. The differences found among the three groups were not statistically significant ( $\mathrm{p}>0.05)$. Length of hospital stay was also similar in all groups of study subjects. Conclusion: Frequency of diabetes among heart failure patients is high and pre-diabetes is not negligible in our country. Future studies in this field should focus on all types of glucose abnormalities rather than previously diagnosed diabetes only.
\end{abstract}

Key words: Diabetes; heart failure; prediabetes; impaired glucose tolerance; impaired fasting glucose.

\section{INTRODUCTION}

Heart failure (HF) is a common, costly, disabling and deadly condition. ${ }^{1}$ In developing countries around $2 \%$ of adults suffer from heart failure, but over the age of 65 , this increases to $6-10 \% 0^{1,2}$.

Diabetes mellitus (DM) is a common co-morbid condition of HF. It has been suggested that DM may play an important role in pathogenesis, prognosis, and response to treatment in heart failure ${ }^{3}$.

Prediabetes is referred to as borderline diabetes, impaired glucose tolerance (IGT), and/or impaired fasting glucose (IFG). Impaired fasting glycaemia or impaired fasting glucose (IFG) refers to a condition in which the fasting blood glucose is elevated above what is considered normal levels but is not high enough to be classified as diabetes mellitus. It is considered a pre-diabetic state, associated with insulin resistance and increased risk of cardiovascular pathology, although of lesser risk than impaired glucose tolerance (IGT). IFG sometimes progresses to type 2 diabetes mellitus. There is a $50 \%$ risk of progressing to overt diabetes over 10 years. A recent study cited the average time for progression as less than three years ${ }^{4}$. IFG is also a risk factor for mortality ${ }^{5}$. 
According to Tenenbaum et al in patients with ischemic heart disease, the incidence of $\mathrm{HF}$ at 6 to 9 years follow-up was $35.7 \%$ in nondiabetic patients, $39 \%$ in patients with impaired fasting glucose and $45.7 \%$ in diabetic patients ${ }^{6}$.

Although diabetes is associated with increased incidence of heart failure, it is unclear whether increasing glucose in the absence of diabetes is a risk factor for heart failure. Subclinical states of increased blood glucose characterized as impaired glucose tolerance or impaired fasting glucose have been recognized to have pathological consequences including macrovascular diseases, increased mortality and left ventricular hypertrophy ${ }^{7}$.

Now-a-days the frequency of diabetes and prediabetes in heart failure patients is increasing worldwide. Increasing trend is also seen in our country. So the aim of this study was to find out the frequency of diabetes and prediabetes in heart failure patients and to assess the associations between diabetes, pre-diabetes and in-hospital outcome of these patients.

\section{MATERIALS \& METHODS}

This cross sectional analytical study was carried out in the departments of Biochemistry and Cardiology of Bangabandhu Sheikh Mujib Medical University (BSMMU), in co-operation with the departments of Cardiology, National Institute of Cardiovascular Diseases (NICVD) and Dhaka Medical College Hospital (DMCH) during the period of July 2010 to June 2011. A total of 250 hospitalized heart failure subjects, age ranging from 25-85 years, of both sexes, were selected in a nonrandom sampling technique. Cases were defined in accordance with World Health Organization criteria for diabetes or prediabetes (impaired glucose tolerance or impaired fasting glucose) and ACC/AHA ( American College of Cardiology/American Heart Association) guidelines for heart failure ${ }^{8}$.

History and clinical data of all patients were collected. Fasting blood sugar was estimated after hospital admission in all subjects not known to be diabetic. OGTT was done for patients with impaired fasting glycaemia.

The patients of heart failure with asthma, chronic obstructive pulmonary disease (COPD), renal failure, liver failure, malignancy, severe anemia, pregnancy or acute myocardial infarction (MI) were excluded from the study.

Study subjects were categorized into diabetic, prediabetic and nondiabetic groups according to their blood glucose findings. Several other risk factors like hypertension, old myocardial infarction, ischemic heart disease, valvular heart disease, cardiomyopathy, and heart block were evaluated.

Frequency of diabetes and prediabetes were measured at $95 \%$ CI. In-hospital outcome was seen in respect of mortality, improvement and length of stay. Outcomes in different groups of heart failure subjects were compared by Chi-square test, unpaired $t$ test and ANOVA test. All comparison tests were done by using computer based SPSS 16.0 for windows software. $\mathrm{P}$ value $<0.05$ was accepted as level of significance.

\section{RESULTS}

Out of the total population ( $\mathrm{n}=250), 32$ had prediabetes, $93 \mathrm{had}$ diabetes. The frequency of prediabetes among the total population was $12.8 \%(95 \% \mathrm{CI}, 8.7-16.8)$ and that of diabetes was $37.2 \%$ (95\% CI, 31.2-43.2\%) (Table 1). Frequency of prediabetes in total population in case of male was $10 \%$ and in case of female was $2.8 \%$. Frequency of diabetes in male and female subjects was $29.2 \%$ and $8.0 \%$ respectively.

Table 1: Frequency of prediabetes and diabetes among study subjects $(\mathrm{N}=250)$

\begin{tabular}{|c|c|c|c|c|}
\hline \multirow[t]{2}{*}{ Group } & & \multirow[t]{2}{*}{ Frequency } & \multicolumn{2}{|c|}{ Prevalence } \\
\hline & & & Point estimate & $95 \% \mathrm{CI}$ \\
\hline \multirow{3}{*}{ Prediabetes } & Both sex & 32 & 12.8 & $8.7-16.9$ \\
\hline & Male & 25 & 10.0 & $6.3-13.7$ \\
\hline & Female & 7 & 2.8 & $0.8-4.8$ \\
\hline \multirow{3}{*}{ Diabetes } & Both sex & 93 & 37.2 & $31.2-43.2$ \\
\hline & Male & 73 & 29.2 & $23.6-34.8$ \\
\hline & Female & 20 & 8.0 & $4.6-11.4$ \\
\hline
\end{tabular}

Among the prediabetic subjects frequency of IGT in total population was $7.2 \%(95 \% \mathrm{CI}, 4.0-10.4)$ and that of IFG was $5.6 \%$ (95\% CI, 2.7-8.5). Frequency of male and female subjects was $6.0 \%$ vs $1.2 \%$ in IGT subjects whereas $4.0 \%$ vs $1.6 \%$ in IFG subjects respectively (Table 2).

Table 2: Frequency of IGT and IFG among study subjects $(\mathrm{N}=250)$

\begin{tabular}{|c|c|c|c|c|}
\hline \multirow[t]{2}{*}{ Group } & & \multirow{2}{*}{ Frequency } & \multicolumn{2}{|c|}{ Prevalence } \\
\hline & & & estimate & $95 \% \mathrm{CI}$ \\
\hline \multirow{3}{*}{ IGT } & Both sex & 18 & 7.2 & $4.0-10.4$ \\
\hline & Male & 15 & 6.0 & $3.1-8.9$ \\
\hline & Female & 03 & 1.2 & $0.0-2.5$ \\
\hline \multirow{3}{*}{ IFG } & Both sex & 14 & 5.6 & $2.7-8.5$ \\
\hline & Male & 10 & 4.0 & $1.6-6.4$ \\
\hline & Female & 04 & 1.6 & $0.0-3.2$ \\
\hline
\end{tabular}

IGT=Impaired Glucose Tolerance, IFG=Impaired Fasting Glucose

Improvement of heart failure was achieved in 27 (84.4\%) cases in prediabetic group, $75(80.6 \%)$ cases in diabetic group and $105(84.0 \%)$ cases in nondiabetic group. Mortality rates in prediabetes, diabetes and nondiabetes were 5 (15.6\%); 18 $(19.4 \%)$ and $20(16.0 \%)$ respectively. The differences found among the three groups were not statistically significant $(p>0.05)$ (Table 3$)$. Length of hospital stay was also similar among all groups of study subjects $(6.6 \pm 0.9$ days in prediabetic subjects, $6.9 \pm 1.9$ days in diabetic subjects \& $6.7 \pm 2.1$ days in nondiabetic subjects, $\mathrm{P}>0.05$ ) (Table 4 ). 
Table 3: Outcomes of study subjects $(\mathrm{N}=250)$

\begin{tabular}{lccccccc} 
Outcome & \multicolumn{2}{c}{$\begin{array}{c}\text { Group I } \\
(\mathrm{n}=32)\end{array}$} & \multicolumn{2}{c}{$\begin{array}{c}\text { Group II } \\
(\mathrm{n}=93)\end{array}$} & \multicolumn{2}{c}{$\begin{array}{c}\text { Group III } \\
(\mathrm{n}=125)\end{array}$} & $P$ value \\
& $\mathrm{N}$ & $\%$ & $\mathrm{~N}$ & $\%$ & $\mathrm{~N}$ & $\%$ & \\
Expired & 5 & 15.6 & 18 & 19.4 & 20 & 16.0 & \\
& & & & & & & 0.784 \\
Improved & 27 & 84.4 & 75 & 80.6 & 105 & 84.0 & \\
\hline
\end{tabular}

$\mathrm{P}$ value was reached from chi square test.

Table 4: Distribution of the study subjects according to duration of hospital stay $(\mathrm{N}=250)$

\begin{tabular}{lccccccc}
$\begin{array}{l}\text { Duration of } \\
\text { stay (day) }\end{array}$ & \multicolumn{2}{c}{$\begin{array}{c}\text { Group I } \\
(\mathrm{n}=32)\end{array}$} & \multicolumn{3}{c}{$\begin{array}{c}\text { Group II } \\
(\mathrm{n}=93)\end{array}$} & \multicolumn{3}{c}{$\begin{array}{l}\text { Group III } \\
(\mathrm{n}=125)\end{array}$} & P value \\
& $\mathrm{N}$ & $\%$ & $\mathrm{~N}$ & $\%$ & $\mathrm{~N}$ & $\%$ & \\
$1-5$ & 10 & 31.25 & 30 & 32.26 & 28 & 22.4 & \\
$6-10$ & 20 & 62.5 & 49 & 52.69 & 87 & 69.6 & \\
$>10$ & 02 & 6.25 & 14 & 15.05 & 10 & 08.0 & \\
Mean \pm SD & $6.6 \pm 0.9$ & $6.9 \pm 1.9$ & $6.7 \pm 2.1$ & 0.112 \\
Range (min-max $)$ & $(4-11)$ & $(2-14)$ & $(2-14)$ &
\end{tabular}

$\mathrm{P}$ value was reached from ANOVA test.

\section{DISCUSSION}

The prevalence of HF with diabetes has accelerated dramatically over the past decades, with $16.9 \%$ in the late 1990 s rising up to $29.1 \%$ in recent years ${ }^{9}$. Our study also reveals very high frequency of DM (37.2\%) among hospitalized patients with HF.

Prevalence similar to the current study has also been observed in different studies ${ }^{10-19}$. In European cohort studies of unselected, unplanned HF admissions, the prevalence of diabetes was $34.7 \%$ in a Spanish cohort ${ }^{10}$. In the Enhanced Feedback for Effective Cardiac Treatment study of 4031 community-based patients presenting with new onset HF at multiple hospitals in Ontario, Canada, from 1997 to 2001, the prevalence of diabetes was $34 \%{ }^{11}$. The Acute Decompensated Heart Failure National Registry (ADHERE) which enrolled 1,05,388 consecutive admissions with acute heart failure in 282 North American hospitals, the overall prevalence of diabetes was $44 \%$. The proportion of HF patients with diabetes in North American hospital cohorts has generally been higher $(30 \% \text { to } 50 \%)^{13-18}$. The analysis from Organized Program to Initiate Lifesaving Treatment in Hospitalized Patients with Heart Failure (OPTIMIZE-HF) demonstrated that a alarming prevalence of DM exists among hospitalized patients with HF, with $42 \%$ of those enrolled having DM documented ${ }^{19}$.

There are some disparities in various studies where prevalence of DM was much lower. In a Japanese study, diabetes was reported in $25 \%$ of admissions with $\mathrm{HF}^{20}$. In a European cohort study of unselected, unplanned HF admissions, the prevalence of diabetes was found $21 \%$ in a French cohort ${ }^{21}$.
In the Danish Investigation of Arrhythmia and Mortality On Dofetilide (DIAMOND) Heart Failure Trial, which included consecutive admissions to 34 Danish hospitals between November 1993 and December 1995 with new or worsening HF, $16 \%$ of patients were diabetic. Diagnosis of diabetes was based on a self-report by the patient or by documentation in the patient's medical records ${ }^{22}$.

Possible explanations of higher prevalence of diabetes in North American subjects are differences in the etiology of HF in those populations. For example, diabetes may be more common in patients with ischemic heart disease than in those with HF due to other causes. Differences in definitions or methods of diagnosis may also explain geographic variation ${ }^{23}$.

Another most important outcome of our study was the frequency of prediabetes in patients with HF. The frequency was $12.8 \%$ in total population, among them IGT was $7.2 \%$ and IFG was $5.6 \%$.

The prevalence of prediabetes among patients with HF is less well documented, and there is even less information on incidence of IGT. The prevalence of glucose intolerance in patients with $\mathrm{HF}$ was reported in several trials range from $23 \%$ to $43 \%{ }^{24-27}$. A recent study conducted in Kameda Medical Center, Chiba, Japan showed that out of 136 subjects 46 $(33.82 \%)$ had prediabetes, among them 9 (9.6\%) had IFG, 37 (39.4\%) had IGT ${ }^{28}$.

This wide range reflects the diverse criteria and methods used to identify patients with glucose intolerance. Many studies investigating the prevalence of dysglycemia in HF used fasting or casual glucose levels or only HbA1c. Fasting plasma glucose and $\mathrm{HbAlc}$ have limited sensitivity for diagnosis of glucose intolerance, in particular IGT. For example, Egstrup et al reported that omitting OGTT would have misclassified $40 \%$ of newly diagnosed cases of diabetes, and by definition all patients with IGT among patients with $\mathrm{HF}^{29}$.

In our study, diabetes was associated with $19.4 \%$ in-hospital mortality whereas mortality rate was $15.6 \%$ in prediabetic group and $16 \%$ in nondiabetic group. These differences of mortality were not statistically significant.

The finding of this study is consistent with a number of studies abroad $^{19,25}$. In Randomized Evaluation of Strategies for Left Ventricular Dysfunction (RESOLVD), diabetic patients had an increased mortality rate, whereas nondiabetic patients also had a similar prognosis ${ }^{25}$. Analysis of short-term clinical outcomes in the OPTIMIZE-HF registry demonstrates that in-hospital mortality rates were similar in patients with DM and those without $^{19}$.

The TEMISTOCLE (hearT failurE epideMIological STudy in itaLian pEople) study showed that in diabetic patients with heart failure all-cause in-hospital mortality rate was similar between diabetics and non-diabetics (5.3 vs $5.7 \%, \mathrm{p}>0.05)^{30}$.

The report of some studies did not support our result. The presence of DM in patients with HF has been associated with an increased risk of poor outcomes ${ }^{11,22,31-34}$. An analysis from the Studies of Left Ventricular Dysfunction trials and registry program demonstrated that the presence of DM in patients with HF resulted in an increased risk for mortality ${ }^{31}$. 
The Beta-Blocker Evaluation of Survival Trial reported a DM prevalence of $36 \%$ among patients with HF enrolled, and on multivariable analysis showed that DM was independently associated with a $22 \%$ increased risk of all-cause mortality ${ }^{33}$.

One of the aims of our study was to see the length of hospital stay which is an important tool for in-hospital outcome. Mean duration of hospital stay in heart failure subjects with diabetes was 6.9 days, prediabetes was 6.6 days and with nondiabetes was 6.7 days. But these differences were not statistically significant.

This finding is not consistent with that of some other studies. Kapoor et al showed that diabetes was independently associated with longer hospital stay but not in-hospital mortality ${ }^{35}$. OPTIMIZE-HF registry demonstrates that patients of HF with DM had longer length of hospital stay and higher rehospitalization rates compared with HF patients without $\mathrm{DM}^{19}$.

In the Reykjavik study, IGT was shown to be an independent predictor of all-cause mortality to a similar degree to that of $\mathrm{DM}^{36}$. In a recent study carried out in Division of Cardiology, Department of Medicine, Kameda Medical Center, Chiba, Japan, it was shown that HF patients with IGT tended to have a higher mortality rate than those without glucose intolerance ${ }^{28}$. Two meta-analyses showed that only post-prandial hyperglycemia, but not fasting hyperglycemia, is a good predictor of adverse cardiovascular events ${ }^{37}$.
In our study outcome scenario was identical in IGT and IFG and DM subjects which was not consistent with previous results. This was possibly from the fact that we only included the hospitalized heart failure subjects and in-hospital outcome was based on mortality and length of hospital stay whereas, in other studies they included both inpatient and outpatient department and long term cohort study was done there. The diagnosis of IGT \& IFG in the Reykjavik study, however, was done on $50 \mathrm{gm}$ OGTT, not $75 \mathrm{gm}$ was used in the present study $^{36}$. The European Guidelines on diabetes, prediabetes, and cardiovascular diseases recommend use of 75-g OGTT ${ }^{38}$.

In this study, we had several limitations. This study was based on a small number of patients. This present study included only patients with $\mathrm{HF}$ who required hospitalization, and thus the data described here cannot be extrapolated to the whole HF population. Information regarding the degree of glycaemic control and diabetes medications other than insulin was not taken properly. For outcome measurement we only evaluated mortality and duration of hospital stay.

\section{CONCLUSION}

Prediabetic patients are prone to develop diabetes later in life. With appropriate measures to control prediabetes, the development of frank diabetes and worse outcome in heart failure patients may be prevented. Further large-scale, prospective clinical trials are necessary to evaluate long term mortality and morbidity of patients of heart failure with diabetes or prediabetes.

\section{DISCLOSURE}

All the authors declared no competing interest. 


\section{REFERENCES}

1. McMurray JJ, Pfeffer MA. "Heart failure". Lancet 2005; 365(9474): 1877-89.

2. Dickstein K, Cohen-Solal A, Filippatos G, McMurray JJ, Ponikowski P, Poole-Wilson A et al. ESC guidelines for the diagnosis and treatment of acute and chronic heart failure 2008: the task force for the diagnosis and treatment of acute and chronic heart failure 2008 of the European Society of Cardiology. Developed in collaboration with the heart failure association of the ESC (FA) and endorsed by the European Society of Intensive Care Medicine (ESICM). Eur Heart J 2008; 29: 2388-442.

3. Bauters C, Lamblin N, Eugene P, Fadden Mc, Van Belle E, Millair A et al. Influence of diabetes mellitus on heart failure risk and outcome. Cardiovascular Diabetology 2003; $2: 1$.

4. Nichols GA, Hillier TA, Brown JB. "Progression from newly acquired impaired fasting glusose to Type 2 Diabetes". Diabetes Care 2007; 30(2): 228-33.

5. Barr EL, Zimmet PZ, Welborn TA. Risk of cardiovascular and all-cause mortality in individuals with diabetes mellitus, impaired fasting glucose, and impaired glucose tolerance: the Australian Diabetes, Obesity, and Lifestyle Study (AusDiab). Circulation 2007; 116(2): 151-57.

6. Tenenbaum A, Motro M, Fisman EZ, Leor J, Boyko V, Mandelzweig L et al. Status of glucose metabolism in patients with heart failure secondary to coronary artery disease. Am J Cardiol 2002; 90: 529-32.

7. Nielson C, Lange T. Blood glucose and heart failure in nondiabetic patients. Diabetes Care 2005; 28(3): 607-11.

8. Hunt SA, Abraham WT, Chin MH, Feldman AM, Francis GS, Ganiats TG et al. ACC/AHA 2005 guideline update for the diagnosis and management of chronic heart failure in the adult. Journal of American College of Cardiology and Circulation 2005; 155-217.

9. Chuan SHI, Ling-jie WANG, Dan-feng HU, Jin-ping LI, Tian-qi ZHU, Ying SHAN et al. Prevalence, clinical characteristics and outcome in patients with chronic heart failure and diabetes. Chin Med J 2010; 123(6): 646-50.

10. Miralda GP, Soriano N, Brotons C, Moral I, Pinar J, Cascant P et al. Baseline characteristics and determinants of outcome in a patient population admitted for heart failure to a general hospital. Rev Esp Cardiol 2002; 55: 571-78.

11. Lee DS, Austin PC, Rouleau JL, Liu PP, Naimark D, Tu JV. Predicting mortality among patients hospitalized for heart failure: derivation and validation of a clinical model. JAMA 2003; 290: 2581-587.

12. Adams KF, Fonarow GC, Emerman CL, LeJemtel TH, Costanzo MR, Abraham WT et al. Characteristics and outcomes of patients hospitalized for heart failure in the United States: rationale, design, and preliminary observations from the first 100,000 cases in the acute decompensated heart failure national registry (ADHERE). Am Heart J 2005; 149: 20916.

13. McDermott MM, Feinglass J, Lee PI et al. Systolic function, readmission rates, and survival among consecutively hospitalized patients with congestive heart failure. Am Heart J 1997; 134: 728-36.

14. Pernenkil R, Vinson JM, Shah AS et al. Course and prognosis in patients $>70$ years of age with congestive heart failure and normal versus abnormal left ventricular ejection fraction. Am J Cardiol 1997; 79: 216-19.

15. Philbin EF, DiSalvo TG. Influence of race and gender on care process, resource use, and hospital-based outcomes in congestive heart failure. Am J Cardiol 1998; 82: 76-81.

16. Philbin EF, McCullough PA, Dec GW et al. Length of stay and procedure utilization are the major determinants of hospital charges for heart failure. Clin Cardiol 2001; 24: 56-62.

17. Smith GL, Masoudi FA, Vaccarino V, Radford MJ, Krumholz HM. Outcomes in heart failure patients with preserved ejection fraction mortality, readmission, and functional decline. J Am Coll Cardiol 2003; 41: 1510-518.

18. Forman DE, Butler J, Wang YF, et al. Incidence, predictors at admission, and impact of worsening renal function among patients hospitalized with heart failure. J Am Coll Cardiol 2004; 43: 61-67.

19. Barry H, Greenberg, William T. Abraham, Nancy M. Albert et al. Influence of diabetes on characteristics and outcomes in patients hospitalized with heart failure. American Heart Journal 2007; 154(2): 277.

20. Tsuchihashi M, Tsutsui H, Kodama $\mathrm{K}$ et al. Clinical characteristics and prognosis of hospitalized patients with congestive heart failure a study in Fukuoka, Japan. Circulation J 2000; 64: 953-59.

21. Cohen-Solal A, Desnos M, Delahaye F et al. A national survey of heart failure in French hospitals. Eur Heart J 2000; 21: 763-69.

22. Gustafsson I, Brendorp B, Seibaek M, Burchardt H, Hildebrandt P, Køber L et al. Influence of diabetes and diabetesgender interaction on the risk of death in patients hospitalized with congestive heart failure. J Am Coll Cardiol 2004; 43: 771-77.

23. Berry C, Brett M, Stevenson K, McMurray JJ, Norrie J. Nature and prognostic importance of abnormal glucose tolerance and diabetes in acute heart failure. Heart 2008; 94: 296 -304.

24. Swan JW, Anker SD, Walton C, Godsland IF, Clark AL, Leyva F et al. Insulin resistance in chronic heart failure: relation to severity and etiology of heart failure. J Am Coll Cardiol 1997; 30: 527-32. 


\section{REFERENCES}

25. Suskin N, McKelvie RS, Burns RJ, Latini R, Pericak D, Probstfield J et al. Glucose and insulin abnormalities relate to functional capacity in patients with congestive heart failure. Eur Heart J 2000; 21: 1368-375.

26. Witteles RM, Tang WH, Jamali AH, Chu JW, Reaven GM, Fowler MB. Insulin resistance in idiopathic dilated cardiomyopathy: a possible etiologic link. J Am Coll Cardiol 2004; 44: 78-81.

27. Goode KM, John J, Rigby AS, Kilpatrick ES, Atkin SL, Bragadeesh T et al. Elevated glycated haemoglobin is a strong predictor of mortality in patients with left ventricular systolic dysfunction who are not receiving treatment for diabetes mellitus. Heart 2009; 95: 917-23.

28. Matsue Y, Suzuki M, Nakamura R, Masami Abe, Maki Ono, Yoshida S et al. Prevalence and prognostic implications of prediabetic state in patients with heart failure. Circ J 2011; 75: 2833-839.

29. Egstrup M, Schou M, Gustafsson I, Kistorp CN, Hildebrandt PR, Tuxen CD. Oral glucose tolerance testing in an outpatient heart failure clinic reveals a high proportion of undiagnosed diabetic patients with an adverse prognosis. Eur J Heart Fail 2011; 13: 319-26.

30. Opasich C, Cafiero M, Scherillo M, De Feo S, Caputo F, Gonzini L et al. TEMISTOCLE investigators. Impact of diabetes on the current in-hospital management of heart failure. From the TEMISTOCLE study. Ital Heart J 2003; 4(10): 685-94.

31. Shindler DM, Kostis JB, Yusuf S, Quinones MA, Pitt B, Stewart D et al. Diabetes mellitus, a predictor of morbidity and mortality in the studies of left ventricular dysfunction (SOLVD) trials and registry. Am J Cardiol 1996; 77: 1017-120.

32. Dries DL, Sweitzer NK, Drazner MH, Stevenson LW, Gersh BJ. Prognostic impact of diabetes mellitus in patients with heart failure according to the etiology of left ventricular systolic dysfunction. J Am Coll Cardiol 2001; 38: 421-28.

33. Domanski M, Krause-Steinrauf H, Deedwania P et al. The effect of diabetes on outcomes of patients with advanced heart failure in the BEST trial. J Am Coll Cardiol 2003; 42: 914-22.

34. Pocock SJ, Wang D, Pfeffer MA et al. Predictors of mortality and morbidity in patients with chronic heart failure. Eur Heart J 2006; 27: 65-75.

35. Kapoor JR, Fonarow GC, Zhao X, Kapoor R, Hernandez AF, Heidenreich PA. Diabetes, quality of care, and in-hospital outcomes in patients hospitalized with heart failure. Am Heart J 2011; 162(3): 480-86.

36. Thrainsdottir IS, Aspelund T, Thorgeirsson G, Gudnason V, Hardarson T, Malmberg K et al. The association between glucose abnormalities and heart failure in the population-based Reykjavik study. Diabetes Care 2005; 28(3): 612-16.

37. Coutinho M, Gerstein HC, Wang Y, Yusuf S. The relationship between glucose and incident cardiovascular events - a metaregression analysis of published data from 20 studies of 95,783 individuals followed for 12.4 years. Diabetes Care 1999; 22: 233-40.

38. Rydén L, Standl E, Bartnik M, Van den Berghe G, Betteridge J, de Boer MJ et al. Task force on diabetes and cardiovascular diseases of the European Society of Cardiology (ESC); European Association for the Study of Diabetes (EASD). Guidelines on diabetes, prediabetes, and cardiovascular diseases: executive summary. European Heart Journal 2007; 28: 88-136. 